\title{
STUDY OF RICKETS IN VIENNA 1919-1922
}

\author{
by
}

\section{DAME HARRIETTE CHICK*}

THE SUBJECT MATTER of my lecture is now history, but at the time, it represented effects which were entirely unexpected and unexplained. In 1919 there were wide reports of hunger osteomalacia in Vienna and when Dr. Elsie J. Dalyell and I, sponsored by the Lister Institute and the Medical Research Council, went to Vienna in the autumn of 1919 to investigate whether the newly reported effects of vitamin deficiency in animals were applicable to man, we found that the newspaper reports had given only half the truth.

Vitamin deficiency was widespread and our message of the cause of its various diseases was received with polite incredulity. But there was one man who believed, Professor K. E. Wenkebach, the well-known heart specialist, Director of the First Medical Clinic of the university and a very influential medical man. He was Dutch and knew of Eijkman's researches in Batavia on beriberi thirty years earlier. ${ }^{1}$ They were wrongly considered only of importance to eaters of polished rice and were published in a Dutch journal. Professor Wenkebach invited us to his house to give an informal talk on what was known as the "newer knowledge of nutrition" to the chief medical men of Vienna, who had been entirely cut off from all international literature describing work in England and America during the war years. Professor Wenkebach suggested that a special meeting be called of the Gesellschaft der Arzte, to be held in the lecture theatre of his clinic, where we should give a formal account.

In the meantime we had succeeded in curing a case of acute infantile scurvy in the University Kinderklinik. There were no oranges in the city, so we laboriously neutralized lemon juice (a very sick infant could not tolerate large amounts of acid) and then reduced it to small bulk in a vacuum and administered it quickly. Further we had treated a case of keratomalacia or corneal ulcer and saved the patient from blindness with butter fat (which we received from the Relief Mission of the Society of Friends). These two dramatic incidents paved the way for our talk to the Gesellschaft der Arzte. It was based almost entirely on experiments with animals which we and American colleagues had done during the war. The talk was long enough to give

\footnotetext{
*Dame Harriette Chick, D.B.E., D.Sc., who celebrated her one-hundredth birthday on 6 January 1975, was awarded the 1974 Prize Lecture of the British Nutrition Foundation for distinguished research in nutrition. Dame Harriette, a member of the scientific staff of the Lister Institute of Preventive Medicine from 1905 to 1970, was one of the first to study vitamins. In 1919 she led a small team sent by the Accessory Food Factors Committee of the Medical Research Council to Vienna to investigate whether the diseases affecting the population in that city were the result of vitamin deficiencies in the diet. Dame Harriette chose the classical work of that team on rickets in children and on vitamin D as the subject of her Prize Lecture.
}

1 C. Eijkman, 'Polyneuritis bij hoenders', Geneesk. nederl. Indië, 1890, 30: 295; 1896, 36: 214. 


\section{Dame Harriette Chick}

the audience plenty to think about and Professor Wenkebach suggested that any discussion should be held later. This took place amid great enthusiasm. Many younger doctors had been prisoners of war in Russian hands and had experienced nightblindness from want of fat. From that time we received ample opportunities for studies to see how far the work with animals applied to man. The application was complete. We found that the fat-soluble vitamin in cod-liver oil was most efficient in curing hunger osteomalacia in elderly adults; but the great retardation of growth in infants was due to repeated attacks of scurvy and rickets together.

We came home in June 1920 and, as much of our work had been done in the Kinderklinik, the Director, Professor Clemens von Pirquet wrote suggesting that we return and make a full-scale attack on rickets in which he proposed to take part. ${ }^{2}$ The Medical Research Council and the Lister Institute through their Accessory Food Factors Committee decided to send such a mission, and I would like to describe the scientific work and results of the mission.

The published report of the Vienna research sets out all the details, and in his preface to it Professor von Pirquet said:

When Dr. Chick and her colleagues on behalf of the Medical Research Council and the Lister Institute began their work in my Klinik in 1919, I had little expectation that it would lead to results of much practical value. At that time I was of the opinion that a vitamin deficiency in our ordinary diet was a very exceptional occurrence, as for example in case of infantile scurvy (Möller-Barlow disease). With regard to the aetiology of rickets I held the view that it was an infectious disease, widely prevalent in this part of Europe, producing severe symptoms only in the case of children who possessed special susceptibility as the result of an inherited tendency, of a faulty diet, or of defective general hygiene. I imagined rickets to be a disease comparable to some extent with tuberculosis. In our towns almost all children are infected with tuberculosis by the time they are 15 years old, but the more severe symptoms of the disease are shown only by those who become infected in the earliest years of life or by those whose resistance is lowered by an inherited disposition to the disease or by the effect of bad nutrition or of other illnesses (as for example measles) contracted after the infection with tuberculosis. In the same way I believed that the more severe symptoms of rickets were shown first by children who become infected shortly after birth, that is to say infants who, in the overcrowded dwellings of the proletariat class, come into contact with other cases of rickets at an early age, secondly by children with an inherited disposition, and finally by those whose susceptibility is increased by secondary causes. ...

The crucial experiment was thus successfully made. The British workers succeeded with the accuracy of a laboratory experiment, in a city where rickets is extremely prevalent, in maintaining a large number of artificially fed babies free from the disease, and further, in the same wards, were invariably successful in healing children admitted with rickets already developed.

With this the chain of evidence appears to me to be complete that animal experiments upon rickets are applicable also to man, that rickets is a disease of nutrition, and that deficiency of fat-soluble vitamin in diet is an essential cause of the disease. ...

\section{RICKETS-CLINICAL AND EXPERIMENTAL}

Rickets in young children, known for centuries as the English disease, was fully described in 1650 by Francis Glisson, Regius Professor of Physic at Cambridge, and also four years earlier in a thesis presented to the University of Leyden by Daniel

2 Richard Wagner, Clemens von Pirquet. His life and work, Baltimore, Md., Johns Hopkins Press, 1968, pp. 118-119.

3 Clemens von Pirquet, preface to Studies of rickets in Vienna 1919-1922 (Report to the Accessory Food Factors Committee appointed jointly by the Medical Research Council and the Lister Institute), Medical Research Council Special Report No. 77, London, H.M.S.O., 1923, pp. 5-6. 


\section{Study of rickets in Vienna 1919-1922}

Whistler, a medical student from Oxford. ${ }^{4}$ The disease is caused by a failure of the cartilage to calcify in the joints of growing children so that they lack stability and bend under the weight of the body. The spine becomes curved, the leg bones are bent and there is swelling around the joints. In severe cases deformities may occur which will last for a lifetime.

Although known as the English disease, rickets has become common in other northern countries and always more prevalent in the cities than in the countryside. Theories advanced for its cause have included a faulty diet as well as defects of hygiene in the environment, such as lack of fresh air, sunshine and exercise. In our present knowledge, achieved chiefly in the second decade of this century, both these factors were found to be involved. In addition there was the inevitable contention that an infective agent, slow acting and of a chronic nature, was to blame, but the evidence for it was never convincing and in the course of time the theory has been abandoned. The true etiology of rickets, as proved and accepted today, was already advanced in the middle of the nineteenth century by Armand Trousseau whose name has persisted in clinical practice as "Trousseau's sign" which demonstrate a deficiency of blood calcium. ${ }^{5}$ He blamed both a faulty diet and a sunless climate for rickets in children, and held that osteomalacia in adults was equivalent to rickets in children, and that both could be cured by cod-liver oil, whereas vegetable oils were useless. This interesting reference was only recently unearthed by Jean Mayer ${ }^{6}$ and Trousseau's conclusions were forgotten although cod-liver oil has long been considered beneficial. An interesting example of this was the result obtained by Bland-Sutton in 1889 who gave cod-liver oil and bones to lion cubs born in the London Zoo and cured their rickets allowing them to survive. ${ }^{7}$ Before his treatment twenty litters of lion cubs had been lost from rickets.

The experimental study of rickets began early in the present century, notably with the work of Sir Edward Mellanby with young dogs. ${ }^{8}$ From a long series of trials he concluded that rickets in puppies was caused by a diet consisting largely of cereals and that prevention or cure depended on the type of fat included in the food. Vegetable oils such as olive oil, cotton-seed oil and linseed oil permitted development of rickets, whereas it could be prevented or cured with cod-liver oil or egg yolk. Mellanby concluded that a vitamin substance preventing rickets was present in these fats.

Additional evidence came from McCollum and his co-workers in Baltimore, who produced a condition akin to rickets in the bones of rats fed on purified diets containing an unfavourable balance of calcium and phosphorus. ${ }^{9}$ This could be prevented if

- G. T. Smerdon, 'Daniel Whistler and the English disease. A translation and biographical note', J. Hist. Med., 1950, 5: 397-415. Edwin Clarke, 'Whistler and Glisson on rickets', Bull. Hist. Med., 1962, 36(1): 45-61.

- A. Trousseau, Clinique médicale de l'Hôtel-Dieu de Paris, Paris, J. B. Baillière, 1861.

- Jean Mayer, 'Armand Trousseau and the arrow of time', Nutr. Rev., 1957, 15(11): 321-323.

7 J. Bland-Sutton, 'Rickets in monkeys, lions, bears, and birds', J. comp. Med. Surg., Phila., 1889 , 10: 1-29.

E. Mellanby, 'The part played by an "accessory factor" in the production of experimental rickets', J. Physiol. Lond., 1918-1919, 52 : xi-xii, liii-liv. E. Mellanby, 'An experimental investigation on rickets', Lancet, 1919, i: 407-412. E. Mellanby, Experimental rickets, Medical Research Council Special Report No. 61, London, H.M.S.O., 1921.

E. V. McCollum, N. Simmonds, H. T. Parsons, P. G. Shipley, and E. A. Park, 'Studies in experimental rickets, I', J. biol. Chem., 1921, 45 : 333. 


\section{Dame Harriette Chick}

certain fats were included. Korenchevsky was able to produce rickets in rats deprived of fat-soluble vitamins, if the animals were very young and only recently weaned at the time of receiving the special diets. ${ }^{10}$ The results of Mellanby were thus confirmed showing the value of certain fats in preventing rickets. It was later shown by the Baltimore workers that the essential nutrient which prevented rickets was different from the fat-soluble vitamin A that prevented xerophthalmia in rats; for when codliver oil or butterfat was oxidized by prolonged heating at $100^{\circ} \mathrm{C}$, the power to prevent xerophthalmia was lost, but the power to prevent rickets was retained. The more heat-stable nutrient factor was called vitamin D. ${ }^{11}$

In the meantime the environmental connexion with the etiology of rickets was being studied by Paton and his colleagues in Glasgow. ${ }^{12}$ These workers were convinced from experiments with puppies that lack of fresh air and exercise was the chief cause of rickets. Puppies brought up in the country and well exercised remained healthy while others reared in the laboratory on a similar diet developed rickets. A bitter controversy arose between the protagonists of the dietetic theory and those supporting the theory implicating fresh air and exercise. At this time no heed was taken of the observations of Huldschinsky in Berlin who found that the ultra-violet radiation from a mercury vapour lamp had a healing effect in rickets. ${ }^{13}$

\section{PRELIMINARY STUDY IN VIENNA}

Much experimental work on deficiency diseases had been carried out during the war years 1914-1918 and rumours and reports came from Vienna of the occurrence of scurvy, rickets and hunger osteomalacia indicating that a situation might exist there which would allow investigation of human deficiency diseases in the light of new knowledge. The accessory Food Factors Committee appointed jointly by the Medical Research Council and the Lister Institute commissioned a preliminary survey of the situation by Dr. Chick, Dr. E. J. Dalyell and Miss E. Margaret Hume, working in Vienna from September 1919 to June 1920. Their observations made in a large foundling hospital in Vienna confirmed the expectation that there were many young children whose growth, bodyweight, activity and general development were considerably below the normal standard for age, and had been so for many months. The backward condition was in no way associated with existing illness and the observations made on the group of children were interesting in that they demonstrated that each child began to approach normal standards when dietary changes were introduced.

A detailed report on nine children was published by Chick and Dalyell in 1921 with the particularly interesting observation on a child with scurvy and rickets who responded well to treatment with vegetable food, fruit juice and cod-liver oil. ${ }^{14}$ It

${ }^{10} \mathrm{~V}$. Korenchevsky, The aetiology and pathology of rickets from an experimental point of view, Medical Research Council Special Report No. 71, London, H.M.S.O., 1922.

${ }^{11}$ E. V. McCollum, N. Simmonds, E. Becker and P. G. Shipley, 'Studies in experimental rickets, XXI', J. biol. Chem., 1922, 53: 293.

12 N. Paton, 'Accessory food factors', Proc. R. Soc. Med. (Sect. Study Dis. Child.), 1920, 13: 77-86.

${ }^{13} \mathrm{~K}$. Huldschinsky, 'Heilung von Rachitis durch Künstliche Höhensonne', Dtsch. med. Wschr., 1919, 45: 712-713. K. Huldschinsky, 'Die Beeinflussung der Tetanie durch Ultraviolettlicht', $Z$. Kinderheilk., 1920, 26: 207-214.

${ }^{14} \mathrm{H}$. Chick and E. J. Dalyell, 'Observations on the influence of foods rich in accessory factors in stimulating development in backward children', Br. med. J., 1921, ii: 1061. 
was then discovered that she had a twin brother in another ward of the hospital who had only the regular diet and the contrast between the two at twenty-eight months of age was most striking. The two disorders, scurvy and rickets, tended to run together in many of the children seen at this time.

\section{PLANNING OF THE MAIN STUDY}

As a result of the preliminary inquiry it was decided to attack the problems of rickets in Vienna in order to obtain confirmation or otherwise of Mellanby's work on dogs, from which he had concluded that rickets could be induced by a specific dietary deficiency extending over a sufficiently long period. It had also been found that the University Kinderklinik, under the direction of Professor Clemens von Pirquet, offered unusual advantages for medical research of any kind upon infants or children. With the exception of the roof sanatorium arranged for treatment and study of convalescent cases of tuberculosis, the resources of the clinic were devoted to the care and study of one hundred patients. The medical staff included the Director with seven senior and twelve junior assistants, there was a nursing staff of about 120 qualified sisters and probationers, and the domestic staff, male and female, numbered about seventy. This liberal allowance of personnel enabled the clinic to discharge the duties not only of a hospital but of an efficient institute for medical study and research.

In the Kinderklinik a system of accurate diet control had been developed by von Pirquet which was well suited to careful study upon young infants. This NEM (Nahrungs-Einheit-Milch) system was a means of allotting and controlling food required for correct nutrition, relating energy requirements to energy value of food..$^{15}$ In the milk kitchen of the clinic, milk was analysed daily and adjusted to the standard value by addition of water or sugar. Cereal food and vegetable purees were made by standard procedures, and all food was prepared under conditions of strict hygiene. The required heat treatment of food may have lowered its content of vitamins B and C. Lemon juice or swede turnip juice was later incorporated into the diet to avoid scurvy.

In the light of such dietary conditions it seemed possible to observe the growth and development of a series of infants during the first year of life upon the regular diet of the clinic, and for comparison upon a diet which would be as great a contrast as possible, with a larger supply of whole milk and fat-soluble vitamins and without addition of extra carbohydrate. Professor von Pirquet was willing to co-operate in such a scheme, and offered a ward of twenty cots and all other facilities for the purpose. Dr. Hans Wimburger, Assistant Radiologist to the clinic, was attached as

15 The NEM was a unit representing the food value of $1 \mathrm{c} . \mathrm{cm}$ of human milk of a standard composition containing 1.7 per cent protein, 3.7 per cent fat and 6.7 per cent sugar; or cow's milk containing 3.4 per cent protein, 3.7 per cent fat and 5 per cent sugar. The NEM has an energy value of 0.67 calorie and the energy requirement for any individual is obtained by a simple calculation based on sitting height. The system as originally formulated was almost exclusively concerned with the quantitative side of nutrition and less regard was paid to the qualitative nature of the food supplied. It was held that protein, fat and carbohydrate were interchangeable as sources of energy if provision was made for a minimum of protein equal to 10 per cent of the total energy value of the diet. In a revision of the diet in 1922 a modification was made to ensure that adequate amounts of vitamins were included. (See Studies of rickets in Vienna 1919-1922, op. cit., note 3 above, pp. 22-24.) 


\section{Dame Harriette Chick}

medical officer to the ward. By the autumn of 1920, with additions to the English team of Dr. Helen M. M. Mackay and Miss H. Henderson Smith, arrangements were completed to begin the second stage of the investigations. From November 1920 to July 1922 the ward was devoted to the study of rickets and, as twenty cots did not allow sufficient numbers to be involved, extra accommodation was found in the Amerikanische Kinderheilstätte at Meidling, a suburb to the south of Vienna. This institution was organized under the general direction of Professor von Pirquet, and the principal members of staff were supplied from the Kinderklinik. Thus the management and the system of diet control was the same. A hut with space for forty cots was made available at Meidling, and with the aid of the Society of Friends Mission in Vienna and a grant from the League of Red Cross Societies it was adapted to have a fine south-facing veranda and the necessary facilities for work with children. The new ward was opened in January 1921 and maintained until May 1922. Thus in the final stage of the study sixty infants could be studied at any one time.

\section{OBSERVATIONS ON THE PROPHYLAXIS AND CURE OF RICKETS}

In the prophylactic series seventy-five infants were under consideration, of whom seventy-two remained under observation for five to fifteen months and three for three to four months. It was important that infants without rickets should be admitted for this observation, but there is difficulty in determining the presence of rickets in its early stages. Age at admission varied from one week to five months, and in fiftyseven cases was under three and one-half months. It was necessary to admit infants at this age because rickets was often present in those aged four months and upwards. At the time of admission none of the infants showed evidence of rickets on X-ray examination, and all were as far as possible free from clinical stigmata of the disease and in good general condition. Many were illegitimate babies already receiving artificial food and below normal in general nutrition. The most important signs for early diagnosis of rickets were craniotabes and marked enlargement of the costochondral junctions. Cranial bossing, enlargement of the epiphyses at wrist and ankle, and bending of the long bones were less useful for early diagnosis. For classification of the results X-ray pictures were taken as criteria of the presence or absence of rickets, and as an indication of the extent of the disease, whether active, healing or healed. On the whole, clinical and X-ray diagnosis showed a close parallel and the X-ray standard was adopted as the $\mathrm{X}$-ray plate provided the clearest and least subjective evidence.

On admission babies were placed in two groups upon diets I and II, care being taken that the groups should be as similar as possible in age and general development. Diet I was that normally used in the clinic and consisted of undiluted local fresh milk with addition of 8 to 10 per cent sugar, and in some cases 17 to 18 per cent sugar. The milk was from stall-fed cows and had very low fat-soluble vitamin content when tested on rats. The cows' fodder consisted of chaff, straw, cereals and roots. From the age of five months cereals were added to the babies' diets and later fresh fruit and vegetables were given. The calorific value was accurately adjusted according to the NEM system. Diet II consisted of a standardized full cream dried milk, prepared to yield a fluid containing 13 per cent solids, protein 3.4 per cent, fat 3.4 per cent, and 


\section{Study of rickets in Vienna 1919-1922}

sugar 5.3 per cent. For infants under three months it was usually necessary to use a greater dilution and to add a small amount of sugar. Additions of cereals were made for older children and all in this group received up to $8 \mathrm{~g}$. cod-liver oil daily. Both groups received daily 5 to $10 \mathrm{cc}$. raw lemon juice, swede juice or tomato juice. There was no significant difference in the fat-soluble vitamin values of the milks used in the two diets. The percentage distribution of the calories in diet I was protein 11, fat 24 and carbohydrate 65; in diet II it was protein 20, fat 45 and carbohydrate 35.

During the summer months, April to October, no rickets developed on either diet, but in the winter period, October to May, fourteen of twenty-four children on diet I became rachitic. Of these, eleven were among thirteen infants admitted below the age of four months and the other three were six to ten months old at admission. The results of this prophylactic series showed conclusively that rickets had a marked winter incidence; that protection in winter could be given by diet; and that infants in the first six months of life were very susceptible to rickets. Some infants having diet I received additions of cod-liver oil and none of these developed rickets.

Curative treatment was instituted for the fourteen infants who developed rickets while on diet I and also for eighteen more severe cases of rickets admitted with the disease between January and April. Cod-liver oil was given to six infants as an emulsion added to their milk, at first in small doses of 1 to $2 \mathrm{~g}$. but increasing as rapidly as possible to 5 to $6 \mathrm{~g}$. Healing processes were demonstrated radiographically within two to four weeks, with calcium deposition in the unossified tissue at the ends of the long bones. The bone picture was gradually restored to normal over a period which depended on the severity of the condition when treatment began. Seven cases were treated by exposure to ultraviolet irradiation from a mercury vapour quartz lamp, as indicated by Huldschinsky. ${ }^{16}$ Healing was established in two to four weeks and the end results were indistinguishable from those obtained with cod-liver oil. Therapeutic exposure to sunlight was applied to a third group of twelve infants from March 1922 and they were out-of-doors for varying periods according to the weather conditions, sometimes for the whole day. The amount of clothing varied with the wind and weather and was gradually reduced until the whole body was exposed when the weather was favourable. Seven cases were exposed to direct sunlight, two were shaded from direct rays of the sun and three had cod-liver oil as well as sun. Each method of treatment was effective in restoring normal bone conditions but those having sunlight and cod-liver oil healed most rapidly. Children treated out-of-doors showed more rapid general improvement than those remaining in the wards while under treatment. Some control cases were observed without special treatment. Infants who developed rickets on diet $I$ in February to April showed progessive lesions until May and then began to show slow recovery. One child showed sudden improvement in bone condition in March, but he occupied a cot in a corner of the ward exposed to direct rays of sunlight through an open window, not through glass, and healing could be attributed to this fact. It also served to stress the difficulty of obtaining a perfect control in observations such as these, and from that time more stringent precautions were taken for obtaining uniform conditions of light intensity.

${ }^{16}$ Huldschinsky, op. cit., note 13 above. 


\section{Dame Harriette Chick}

Cases admitted with rickets, while undergoing the preliminary periods of observation in diet I served to establish one important fact. By transfer to hospital, conditions of air space, ventilation, cleanliness, freedom of movement and general hygiene were markedly improved for the majority who had previously been in very poor surroundings. During April and May windows in the wards were open for long periods and the children enjoyed plenty of fresh air. Until April there was little spontaneous healing and healing in those kept indoors was slow in comparison with those outside in sun or shade. Conclusive evidence of prophylaxis by means of diet where food and external conditions were strictly controlled had not been previously recorded. The protective action of diet II was probably attributable to the small quantity of cod-liver oil it contained. The other main difference between diets I and II was the substitution of sugar by milk, but diet I proved curative in spring when cod-liver oil was added and no evidence was obtained to implicate the excess of carbohydrate and the smaller allowance of fat and protein in this diet as producing rickets. It must be admitted that no special investigation was made to elucidate this point, but the common occurrence of rickets in breast-fed infants in Vienna was an interesting fact in this connexion.

The observation upon seasonal incidence was in accordance with the wide experiences of clinicians that rickets developed in winter and spring and healed in summer. The results of sunlight therapy confirmed the clinical observations of Hess and his co-workers in 1921 and supported their theory that the seasonal incidence of rickets was due to the seasonal variation of sunlight. ${ }^{17}$ The value of sunlight in prevention of rickets in rats was demonstrated by Hess's team, ${ }^{18}$ and in 1922 by McCollum and his colleagues ${ }^{19}$ following the important observations of Huldschinsky in 1919 and $1920 .{ }^{20}$ It seemed that the action of sunlight might depend on the ultraviolet rays it contained. In a world review of rickets in 1906 Hansemann concluded that the disease could not be explained by dietary deficiencies and that lack of fresh air and free movement for the children was responsible. ${ }^{21} \mathrm{~A}$ similar conclusion was arrived at by Findlay in $1908,{ }^{22}$ Paton et al. in $1918,{ }^{23}$ and Findlay and Ferguson in 1918. ${ }^{24}$ Their observations, particularly the analysis of the occurrence of rickets in Glasgow in relation to various hygienic conditions and opportunities for exercise in the open air indicated that a faulty diet, if at all responsible, was not the sole factor. The observations on the babies in Vienna gave no evidence that fresh air or exercise produced any effect apart from the concomitant greater exposure to sunlight, and could be held to prove that at times of minimal isolation, as during winter, diet

${ }^{17}$ A. F. Hess, L. J. Unger and A. M. Pappenheimer, 'Experimental rickets; the prevention of rickets in rats by exposure to sunlight', Proc. Soc. exp. Biol. Med., N.Y., 1921-22, 19: 8-12.

18 Ibid.

${ }^{19}$ McCollom et al., op. cit., note 11 above.

${ }^{20}$ Huldschinsky, op. cit., note 13 above.

${ }^{21}$ D. von Hansemann, 'Ueber Rachitis als Volkskrankheit', Berl. klin. Wschr., 1906, 43: 249-254.

${ }^{22}$ L. Findlay, 'The etiology of rickets: a clinical and experimental study', Br. med. J., 1908, ii: 13-17.

${ }^{28}$ N. Paton, L. Findlay and A. Watson, 'Observations on the cause of rickets', Br. med. J., 1918, ii: $625-626$.

${ }^{24}$ L. Findlay and Margaret Ferguson, $A$ study of social and economic factors in the causation of rickets, with an introductory historical survey, Medical Research Council Special Report No. 20, London, H.M.S.O., 1918. 
was the controlling factor. The most interesting result of the study on prophylaxis and healing was the identical action of cod-liver oil and of light therapy, natural or artificial, on the bone lesions in rickets. This fact, while explaining the prevalence of rickets in northern climates and large cities, could at the same time account for its non-occurrence in Greenland where large amounts of fish oils were consumed by the mothers and older children.

The results attributing the action of cod-liver oil to its content of fat-soluble vitamin also led to the idea of the possibility of synthesis of the vitamin in the animal body under the influence of radiation from the sun. This was an entirely new concept at that time and only considerable animal and clinical study that arose from the Vienna work served to advance the fuller knowledge of the fat-soluble vitamins and all that we now know of the formation of the active antirachitic factor from precursors in the skin and in foods by the action of ultraviolet radiation from sunlight or artificial sources. In fact the role of sunlight in the prevention of rickets was not a new discovery in 1920, for thirty years earlier Palm, in a study of the geographical distribution of rickets, had concluded that its occurrence was inversely related to the incidence of sunshine. ${ }^{25}$ From his own experience in medical practice in Japan and from the reports of other physicians in tropical countries where sunshine was abundant and diets poor, he concluded that sunlight was the great preventive of the disease. He pointed out also that the chief foci of rickets in children were the industrial cities of northern Europe where the natural lack of sun was further increased by the smokey atmosphere.

The study in Vienna indicated the age of greatest susceptibility to rickets to be the first six months of life. This was shown by the excellent X-ray diagnosis carried out by Dr. Wimberger and in the final report of the work the inclusion of many typical $\mathrm{X}$-ray plates shows the value of his aid throughout the study. ${ }^{26}$

Routine tests were made by Miss Hume on the fat-soluble vitamin value of the milk used for the infants by experiments with rats carried out at the clinic. Both the dried milk and the fresh milk had low values and the value of the fresh milk remained low throughout the year. No improvement could be detected in the milk of cows kept in stalls and fed intensively with fresh green food. Milk of a constant but low value was obtained on a diet of cereals, chaff, straw and roots, without greenstuff, fresh or dried. The problem of the relation of the cow's diet to the fat-soluble vitamin content of its milk was not solved in the context of the Vienna study, but later observations on milk and butter from cows on good summer pasture indicated that the method of stock-keeping was important in determining the vitamin content of the milk.

It certainly seemed clear that in Vienna, and possibly also in England, the summer disappearance of rickets was due not to seasonal alterations in the fat-soluble vitamin content of the milk but to seasonal alterations in the light available to the children. It was considered a theoretical possibility that where the borderline between rickets and no rickets was narrow, some infants might be saved from crossing it in winter, by receiving more light than their fellows who do cross it, while others might be saved by receiving more and better milk.

${ }^{25}$ T. A. Palm, 'The geographical distribution and aetiology of rickets', Practitioner, 1890, 45: $270,321$.

26 Studies of rickets in Vienna 1919-1922, op. cit., note 3 above, passim. 


\section{Dame Harriette Chick}

A study was also made of the milk of mothers with rachitic infants and it proved to be of very low vitamin value. Mothers with non-rachitic infants gave milk of better vitamin values. Some tests were made after supplementary feeding with extra butter and cod-liver oil, and indicated that the vitamin value of the milk was readily improved in women who were relatively well nourished at the beginning of the trial, but in ill-nourished women the vitamin seemed to be absorbed by their own requirements and not immediately transferred to their milk. This was a small series but an interesting addition to the study.

HUNGER-OSTEOMALACIA IN VIENNA AND ITS RELATION TO DIET

Hunger-osteomalacia, a condition with symptoms resembling the early stages of osteomalacia of pregnancy, was first reported in Vienna in the late autumn of 1918.27 The disease affected chiefly elderly persons of both sexes from the poorest section of the population. It was characterized by pain on body movement, a waddling gait, difficulty in mounting stairs, severe pain in the sacral region on pressure, and pain in the ribs on compression of the thorax. It was frequently associated with tetany. The incidence increased throughout the winter and spring of 1918-1919 but showed a marked remission in the summer of 1919. It was again prevalent in the winter and spring of 1919-1920 and many sufferers seemed to be relapsed cases from the previous winter, who had shown partial or complete recovery during the summer. The patients gave a history of subsistence mainly on bread and vegetables with absence from the diet of meat, animal fats, eggs and milk.

In January 1920 opportunity was afforded for a study of dietary therapy upon a series of severe cases with a view to the elucidation of the etiology of the disease. Comparative observations were made of the effects of various additions to the diet in thirty-nine cases under hospital and institutional conditions. In addition, from February to June 1920 an investigation was made of 177 outpatients with hungerosteomalacia. Twenty-one cases were treated in a convent which had suffered very severely from the food deprivation in Vienna. Approximately equicaloric additions to the diet were made of sugar, cereal and olive oil, or of margarine and olive oil, or of butter, cod-liver oil and dried egg. The first group had $15 \mathrm{~g}$. extra fat and the other two $\mathbf{4 0} \mathrm{g}$. extra fat. Five patients in the first group who had very mild symptoms showed some improvement but five others with severe symptoms made no progress until they were given the butter and cod-liver oil supplement. A few of those having margarine and olive oil improved and all who had the butter, cod-liver oil and egg improved very rapidly. Some severe cases in hospital were treated also and ability to walk was restored within three weeks by the butter, cod-liver oil and egg supplement.

The 177 ambulatory cases were given varying doses of cod-liver oil or a vegetable oil with added phosphorus. The best results were obtained with the highest doses of cod-liver oil, but some progress was noted with the vegetable oil. The results of the study may have been influenced by seasonal alterations in light, as only a few were studied in February and the rest in March, April and May. A record of the monthly incidence of new studies has been made on the effects of the calcium and phosphorus

27 Ibid., pp. 188-194. 
balance in the diet on bone growth but no information was obtained on the content of these components in the diets in Vienna and the full knowledge of the mineral balance was a matter for later clinical and experimental investigation.

Similarly in the investigations on late rickets in older children and with hungerosteomalacia in older adults, involvement of a dietary factor related to the fat-soluble vitamin of cod-liver oil was demonstrated, together with exposure to sunlight or seclusion indoors.

This full report of the Vienna research ${ }^{28}$ has been the means of stimulating much further study to elucidate the many questions raised inevitably by such clinical research. The understanding of the effect of ultraviolet light in converting a precursor of vitamin $D$ in the skin into an active form of the vitamin followed only a few years after the work in Vienna and as Dr. Kodicek told us last year so much more is now known of the nature of vitamin D-as vitamin or hormone. ${ }^{29}$

28 Ibid.

99 E. Kodicek, 'The story of vitamin D. From vitamin to hormone', Lancet, 1974, i: 325-329. See also, E. Kodicek, 'Excerpts from "The story of vitamin D-from vitamin to hormone", British Nutrition Foundation Prize Lecture 1973', Bull. Br. nutr. Found., No. 11 (May 1974), pp. 33-37. 